logical examination. Our figures might therefore indicate a " normal" rate of occurrence (about $5 \%$ ) of penicillin-resistant strains of Staph. pyogenes.-I am, etc.,

Kosice, Czechoslovakia.

I. FriedmanN.

\section{Pica for Pipes}

SIR,-I recently encountered rather an unusual instance of pica (craving for unnatural food) in pregnancy, which may be of interest to your readers. The patient, a woman of 36 years, had 14 pregnancies -10 full-term and 4 miscarriages. She was recently in hospital for her fourth miscarriage, with which she had a severe haemorrhage necessitating a blood transfusion. When she was later persuaded to swallow iron in the shape of ferrous sulphate for her still present anaemia, she declared she would sooner have some clay pipes to eat.

It transpired that during all her pregnancies (and most of her married life seems to have been spent in the pregnant state) she developed a craving for clay--generally in the form of clay pipes. which were, at one time at any rate, cheap to buy and easily procurable. She has good strong teeth and evidently experiences no difficulty in the mastication of the pipes, and when she cannot obtain the latter she eats pipe-clay, as used for cleaning stairs. She remarked jocularly that her doctor used to try and dissuade her from her practice by warning that she would give birth to "stooky weans." De Lee (1947) makes a reference to the desire for clay, among other unnatural foods, by certain pregnant women.-I am, etc.,

Bellshill, Lanarkshire.

JOHN M. KING.

\section{REFERFNCE}

De Lee, J. B., and Greenhill, J. P. (1947). Principles and Practice of Obstetrics, 9 th edition, W. B. Saunders, Philadelphia, p. 83.

\section{New South Wales Branch of B.M.A. and R.M.B.F.}

SIR,-I hope you will allow me through your columns to record the indebtedness of the Royal Medical Benevolent Fund to the New South Wales Branch of the British Medical Association. All your readers will like to know of the great generosity of the members of the New South Wales Branch who have recently sent 360 food gift parcels to beneficiaries of this fund. This is such a warm-hearted and kindly action on the part of our colleagues overseas that I feel all members of the profession living in the home country will join with me in thanking our many friends in New South Wales.-I am, etc., Alfred WebB-Johnson, President, Royal Medical Benevolent Fund.

\section{POINTS FROM LETTERS}

\section{Splints from Spatulas}

Mr. A. MacDiarmid (Thames, New Zealand) writes: Take an ordinary wooden tongue spatula and introduce it into the steam in a boiling sterilizer. To do this, lower the lid so that it holds the end of the spatula against the edge of the side of the sterilizer. Leave the spatula to steam for about a minute and then take it out. It is now pliable and can be bent to the desired shape between the fingers and thumb. It should be held thus until it dries, hardens, and maintains its shape. In this way it is easy to produce a curved splint or one with several angles of 45 degrees. The splint can be padded with a strip of adhesive felt. Do not put the splint in the water or it will become too wet.

\section{Always in the House}

A Doctor's WIFE writes: "My dear, I never pass a day but I think how lucky you are to have a doctor in the house."... So speaks one of the best patients as one is laboriously toiling up the hill with a pram, having abandoned that wretched phone to the fates for an hour. Summer isn't quite so bad, but let me sympathize with all those other poor miserable creatures whose bed-companion is the telephone and whose days are spent keeping food eternally at a reasonable temperature so that the patient may have his doctor. Then, what of the evenings ? Mentally and physically exhausted, the evening surgery done, and the last sickly patient tucked safely into bed, home comes the doctor to yet another sliding meal-eight, nine, ten-whatever the whim takes him. The newspaper, a pipe, and after a few minutes loud catarrhal snores. What a cheerful evening! Woe betide the wife who inquires for medical remedies at this juncture; they are doomed to be cast off as mere psychological flights of fancy. Better to keep one's thoughts of aching chilblains or children's spots deep in the crevices of the mind. What is there to it ? One often wonders; and still every medical school pours out its numerous doctors, and a thousand crazy females go and land themselves into this heaven, with a doctor "always" in the house.

\section{Obituary}

\author{
G. F. STEBBING, M.B., F.R.C.S.
}

Mr. G. F. Stebbing, a pioneer of radiotherapy in this country and an outstanding personality, died at his home on Dec. 22 at the age of 63 , after a long and painful illness, borne with characteristic optimism and courage. Like many other medical men he succumbed to a disease to the treatment of which he had devoted himself for many years.

George French Stebbing was educated at Guy's Hospital and qualified in 1906, taking the conjoint diploma and the M.B., B.S. with honours and distinction in surgery. After completing his house appointments he told Mr. Symonds, later Sir Chartres Symonds, whose house-surgeon he had been, about the kind of institutional work he would like to do. Sir Chartres replied that he knew of no such place and that Stebbing must create it for himself. In 1908 Stebbing went to the Lambeth Infirmary, and with the encouragement of the late medical superintendent, Dr. A. L. Baly, he developed the clinical side there and so rapidly raised the standard of work that by 1914 Lambeth Infirmary was held in high esteem by both the local populace and general practitioners. After a period of service in the Navy he returned to Lambeth Hospital, where he remained a leading light until the day of his death. In 1934 he was elected a Fellow of the Royal College of Surgeons and recently was a member of the Council of the College. He was made a Fellow of the Faculty of Radiology in 1939.

In his early years he devoted himself to all branches of medicine and surgery, and with his tremendous capacity for work and wide reading he became a "G.P." in the very best sense of the term. Many old Lambeth medical officers and nurses have reason to thank "Steb," or the "Great White Chief" as he was affectionately termed (he wore a long white coat not usual in those days), for all he taught them. His experience was so great that his phrase, "I am quite familiar with that," disappointed many a junior colleague who felt he had produced a problem for his chief.

Some twenty-five years ago Stebbing became interested in the use of radium for the treatment of malignant disease, and in 1929 arrangements were made between the Lambeth Board of Guardians and the Ministry of Health to provide Lambeth Hospital with radium and deep $x$-ray therapy plant, which was to be available for the treatment of patients not only from the district but from any part of London. Stebbing visited all the principal clinics in this country and on the Continent, and the information he obtained was applied in equipping the new department. As a first-class surgeon and radiotherapist, a rare combination, he achieved great success in a great number of patients, and even when this was not possible the confidence that he inspired and the infinite pains he took with palliative measures brought comfort to many sad cases.

- Stebbing will always be remembered by his contemporaries for his wide interests both inside and outside the hospital. He was a member and honorary secretary of the Radium Commission from its formation in 1929. He was chairman of the London and Counties Medical Protection Society. He was largely responsible for the establishment of the L.C.C. Clinical Research Committee and was its first chairman. From this there developed the L.C.C. Medical Society, of whose first council he was chairman. He was also for many years examiner in radiology for the Conjoint Board. He had the faculty of always being able to interest himself in anything which interested his friends and acquaintances. He was a fine team worker and was never found unwilling to see any case a colleague desired him to see. An American visitor to his clinic once described him as the "human dynamo," a tribute to his amazing energy. His direct approach to the things that mattered and his dislike of non-essentials were characteristic. $\mathrm{He}$ inspired complete confidence and affection in his patients and he could remember them years afterwards and what he had done for them. He was a fine lecturer and clinical teacher. 